\title{
The Importance of Serum Serotonin Levels in the Measurement of Radiation-Induced Bystander Cell Death in HaCaT Cells
}

\author{
Fiona Lyng \\ Technological University Dublin, fiona.lyng@tudublin.ie \\ Maxine Desplanques \\ Technological University Dublin \\ K.K. Jella \\ Technological University Dublin
}

See next page for additional authors

Follow this and additional works at: https://arrow.tudublin.ie/radart

Part of the Medicine and Health Sciences Commons

\section{Recommended Citation \\ Lyng, F., Desplanques, M. \&Kumar, J. (2012). The Importance of Serum Serotonin Levels in the Measurement of Radiation-Induced Bystander Cell Death in HaCaT Cells. International Journal of Radiation Biology,vol. 88, no. 10, 2012. 10.3109/09553002.2012.705222}

This Article is brought to you for free and open access by the Radiation and Environmental Science Centre at ARROW@TU Dublin. It has been accepted for inclusion in Articles by an authorized administrator of ARROW@TU Dublin. For more information, please contact arrow.admin@tudublin.ie, aisling.coyne@tudublin.ie, gerard.connolly@tudublin.ie.

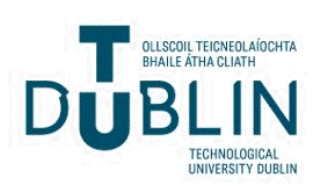




\section{Authors}

Fiona Lyng, Maxine Desplanques, K.K. Jella, Amaya Garcia, and Brendan McClean

This article is available at ARROW@TU Dublin: https://arrow.tudublin.ie/radart/50 
The importance of serum serotonin levels in the measurement of radiationinduced bystander cell death in HaCaT cells

Lyng F.M. ${ }^{1 *}$, Desplanques M. ${ }^{1}$, Kumar Jella K. ${ }^{1}$, Garcia A. ${ }^{1}$ and McClean B. ${ }^{2}$

${ }^{1}$ DIT Centre for Radiation and Environmental Science, Focas Research Institute, Dublin Institute of Technology, Kevin St, Dublin 8, IRELAND

${ }^{2}$ St Luke's Hospital, Highfield Road, Rathgar, Dublin 6, IRELAND

Running title: Importance of serum serotonin levels in bystander effects Keywords: bystander effects, serotonin, serum, cell death, Alamar blue assay, clonogenic assay

*Person to whom all correspondence should be sent:

Dr Fiona M Lyng

DIT Centre for Radiation and Environmental Science

Focas Research Institute

Dublin Institute of Technology

Kevin St, Dublin 8, IRELAND

Tel: $\quad$ ++ 35314027972

Fax: ++ 35314027904

Email: fiona.lyng@dit.ie 


\section{Abstract}

Purpose: The aim of this study was to investigate the importance of serum serotonin levels in the measurement of bystander cell death. The study was undertaken as part of an intercomparison exercise involving seven European laboratories funded under the European Union Sixth Framework Programme (FP6) Non-Targeted Effects (NOTE) integrated project.

Materials and Methods: Three batches of foetal bovine serum were tested; serum with high and low serotonin content from the intercomparison exercise as well as serum from the home laboratory. Three sets of human keratinocytes (HaCaT cell line) were cultured in DMEM:F12 medium supplemented with serum with high or low serotonin content or serum from the home laboratory and both donor and recipient HaCaT cells were plated. The donor HaCaT cells were irradiated (0.5 Gy) using a cobalt 60 teletherapy unit, the medium was harvested one hour post irradiation and transferred to the recipient HaCaT cells. Bystander induced cell death was measured by the clonogenic survival assay and the Alamar blue viability assay.

Results: A significant reduction in cell survival, as measured by the clonogenic assay, and in cell viability, as measured by the Alamar blue assay, was observed in the recipient $\mathrm{HaCaT}$ cells treated with medium from irradiated cells compared to the cells treated with medium from unirradiated cells. No significant difference was found between the three batches of serum. 
Conclusions: The data suggest that in our cell system and with our endpoints (clonogenic assay and Alamar blue assay), serum serotonin levels do not play a role in bystander induced cell death. 


\section{Introduction}

Recent work has suggested that serum serotonin levels may play a role in the expression of radiation-induced bystander effects (Mothersill et al 2010). Serotonin levels were found to vary widely between batches of commercially available foetal bovine serum and the magnitude of the bystander response (reduction in cloning efficiency) was found to correlate with the measured serotonin levels. The authors suggested that variability in serum serotonin levels could explain some of the variation in the ability to produce bystander effects observed between laboratories. As part of the European Union Sixth Framework Programme (FP6) Non-Targeted Effects (NOTE) integrated project, an interlaboratory exercise was undertaken by seven European laboratories in collaboration with Prof Mothersill. This paper describes the results from the Radiation and Environmental Science Centre (RESC) laboratory, Dublin Institute of Technology, Ireland. The importance of serum serotonin levels in the measurement of bystander cell death was investigated in the HaCaT cell line.

Bystander cell death was measured using the gold standard clonogenic assay and using the Alamar blue cell viability assay. The active ingredient of Alamar blue is resazurin which is a nontoxic, cell permeable compound that is blue in colour and virtually nonfluorescent. Upon entering viable cells, resazurin is reduced to resorufin, which produces red fluorescence which can be measured quantitatively using a microplate reader. The fluorescence intensity is proportional to the number of living / viable cells. Damaged and nonviable cells 
have a lower metabolic activity and will show reduced fluorescence intensity compared to viable cells. This assay has been shown to be more sensitive than the 3-(4,5-Dimethylthiazol-2-yl)-2,5-diphenyltetrazolium bromide (MTT) cell viability assay (Hamid et al 2004). The Alamar blue assay has been used previously by our group (Lyng et al 2011) to measure bystander induced cell death and shows comparable results to the clonogenic assay when the assay is performed at 96 hours after exposure.

In the present study, two samples of foetal bovine serum with low and high serotonin levels were provided by Prof Mothersill for the intercomparison exercise. Bystander cell death was measured using both the clonogenic assay and the Alamar blue assay in a human keratinocyte cell line, HaCaT cells, cultured in medium supplemented with the different sera. 


\section{Materials and Methods}

Cell Culture

Human keratinocytes, HaCaT cell line (Cell Lines Service, Germany) were cultured in Dulbecco's Modified Eagle Medium (DMEM): Nutrient Mixture F-12 Ham (F12) (1:1) medium (Sigma, Dorset, U.K) containing $10 \%$ foetal bovine serum (see below), 1\% penicillin-streptomycin solution 1000IU (Gibco, Irvine, U.K) and $1 \mu \mathrm{g} / \mathrm{ml}$ hydrocortisone (Sigma). Cells were incubated under humid conditions at $37^{\circ} \mathrm{C}$, with $5 \% \mathrm{CO}_{2}$ in air. Subculture was routinely performed when cells were $80 \%$ confluent, using a $1: 1$ solution of $0.2 \%$ trypsin (Sigma) and $1 \mathrm{mM}$ versene (Sigma) at $37^{\circ} \mathrm{C}$.

Foetal Bovine Serum samples

$10 \mathrm{ml}$ of each serum sample (Gibco 10270-106, lot no 41Q2190K (home laboratory serum), and serum samples with high and low serotonin levels) was added to $90 \mathrm{ml}$ DMEM:F12 medium with supplements. Each media sample was aliquoted, wrapped in foil and all handling was performed with minimum lighting.

\section{Irradiation}

T25 flasks (Sarstedt, Wexford, Ireland) containing approx $2 \times 10^{5}$ cells in $5 \mathrm{ml}$ medium were irradiated (0.5Gy) at room temperature using a cobalt 60 teletherapy unit delivering approximately $1.5 \mathrm{~Gy} / \mathrm{min}$ during the time period of these experiments. The source to sample distance was 80 centimetres and the 
field size was $30 \times 30$ centimetres. Control flasks were sham irradiated. Cells were returned to the incubator immediately after irradiation.

Irradiated Cell Conditioned Media (ICCM) harvesting

Medium from irradiated and unirradiated cells was poured off donor flasks one hour after irradiation and filtered through a $0.22 \mu \mathrm{m}$ filter (Nalgene/Thermo Fisher, Hereford, UK) to ensure that no cells could still be present in the transferred medium. Recipient cells were exposed to ICCM as detailed below.

\section{Clonogenic assay}

Recipient cells were seeded at 400 cells per T25 flask. Following exposure to 5 $\mathrm{ml} \mathrm{ICCM}$, cells were incubated for 7 days, after which the colonies were stained using a $20 \%$ carbol fuchsin $(\mathrm{BDH}, \mathrm{UK})$ solution for 5 minutes and scored. The clonogenic assay was performed in triplicate for two independent experiments.

Alamar blue cell viability assay

Recipient cells were seeded at 2,000 cells per well, in a 96 well micro-plate (Nunc, Roskilde, Denmark) and maintained at $37^{\circ} \mathrm{C}$ for 24 hours. This was found to be the optimal cell number to achieve the desired confluency (80-90\%) following 96 hours incubation. To negate the effects of medium evaporation from the outer wells of the microplate, only the internal 60 wells were used for testing and sterile phosphate buffered saline (PBS) was added to the outer wells. The original medium was removed, and $100 \mu \mathrm{I}$ ICCM was placed in each test well, for 
96 hours. Following exposure, the cells were washed with PBS. 5\% Alamar blue (Invitrogen, BioSciences, Dublin, Ireland) in DMEM F-12 without phenol red (Sigma) was added to each well for 3 hours. Alamar blue is a dark blue nonfluorescent resazurin dye which is reduced to a pink and highly fluorescent resorufin dye through a redox reaction in the cytoplasm, the level of which can be correlated to cellular proliferation and metabolism. Alamar blue fluorescence was measured using the TECAN GENios (Grodig, Austria) microplate reader at an excitation wavelength of $540 \mathrm{~nm}$ and emission wavelength of $595 \mathrm{~nm}$. The resulting fluorescence intensities were normalised to the control for each sample. The Alamar blue assay was performed for four independent experiments with six replicate wells for each test ICCM.

\section{Statistical analysis}

The data are expressed as the percentage mean \pm standard error on the mean, for each of three independent experiments. Significance was assessed using the Student's t-test at $p<0.05$. 


\section{Results and Discussion}

In this study, bystander induced cell death was assessed in the HaCaT cell line using both the clonogenic assay and the Alamar blue cell viability assay. Three

different batches of foetal bovine serum were tested to investigate the importance of serum serotonin levels in bystander induced cell death; the home laboratory serum (supplied by Gibco, UK) and two sera from the NOTE intercomparison exercise showing low and high serotonin levels. .

A significant reduction in cell survival as measured by the clonogenic assay was observed in $\mathrm{HaCaT}$ recipient cells treated with medium from irradiated $\mathrm{HaCaT}$ donor cells (0.5Gy irradiated cell conditioned medium (ICCM)) compared to cells treated with medium from unirradiated HaCaT donor cells (OGy ICCM) (figure 1). Similarly, a significant reduction in cell viability as measured by the Alamar blue assay was observed in the recipient HaCaT cells treated with 0.5Gy ICCM compared to those treated with OGy ICCM (figure 2).

However, no significant difference was found between the three batches of serum; serum samples with high and low serotonin content and the home laboratory serum. It is not clear why we did not observe an effect of the serum serotonin level on bystander cell death similar to that observed by Mothersill et al (2010). One explanation may be due to the mutant p53 expression in the HaCaT cell line used in our study compared to the wild type p53 expression (although only $30 \%$ of normal expression) in the HPV-G cell line used by Mothersill et al (2010). A recent paper by Mothersill et al (2011) has shown that both p53 null 
and wild type cells can produce bystander signals but only p53 wild type cells could respond to the bystander signals. This may explain the differences in results for each of the cell lines.It is important to note that this is a preliminary study and part of a wider intercomparison study between seven European laboratories. Clearly, additional work could be performed to categorically prove that serotonin levels do not play a role in bystander effects in this particular cell line, eg. additional radiation doses and radiation types and additional endpoints. In conclusion, our results suggest that in HaCaT cells, serum serotonin levels do not play a role in bystander induced cell death, as measured by the clonogenic assay and the Alamar blue assay. 


\section{Acknowledgements}

The authors are very grateful to St Luke's Hospital, Dublin for continued access to the cobalt-60 radiotherapy source.

\section{Declaration of Interest}

The authors acknowledge financial support from the FP6 Integrated Project, Nontargeted effects of ionising radiation (NOTE) FI6R 036465. 


\section{References}

Hamid R, Rotshteyn Y, Rabadi L, Parikh R, Bullock P. (2004), Comparison of alamar blue and MTT assays for high through-put screening. Toxicology In Vitro. 18: $703-710$.

Lyng FM, Howe OL, McClean B. (2011), Reactive oxygen species-induced release of signalling factors in irradiated cells triggers membrane signalling and calcium influx in bystander cells. International Journal of Radiation Biology 87: $683-695$

Mothersill C, Saroya R, Smith RW, Singh H, Seymour CB. (2010), Serum serotonin levels determine the magnitude and type of bystander effects in medium transfer experiments Radiation Research 174: 119-123.

Mothersill C, Bristow RG, Harding SM, Smith R, Mersov A, Seymour C. (2011), A role for p53 in the response of bystander cells to receipt of medium borne signals from irradiated cells. International Journal of Radiation Biology 87: 11201125. 


\section{Legends for Figures}

Figure 1 Clonogenic survival (\%)of HaCaT cells exposed to 0Gy and 0.5Gy ICCM. Errors indicate the standard error of the mean (SEM) for $n=2$ independent experiments, ${ }^{*} p<0.05$

Figure 2 Viability of HaCaT cells exposed to 0Gy and 0.5Gy ICCM. Cell viability was measured using the Alamar blue assay. Errors indicate the standard error of the mean (SEM) for $n=4$ independent experiments, * $p<0.05$ 


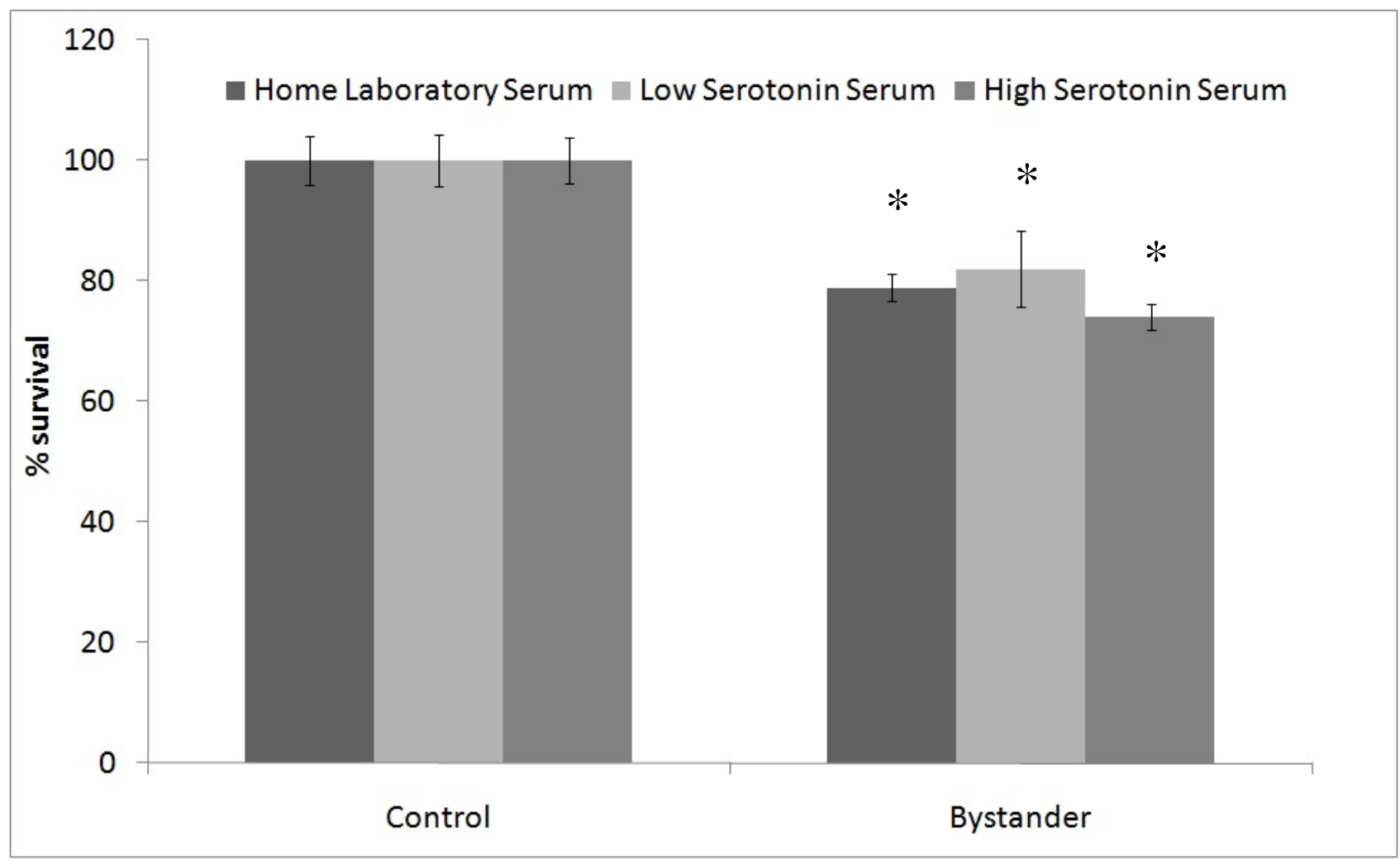

Figure 1 


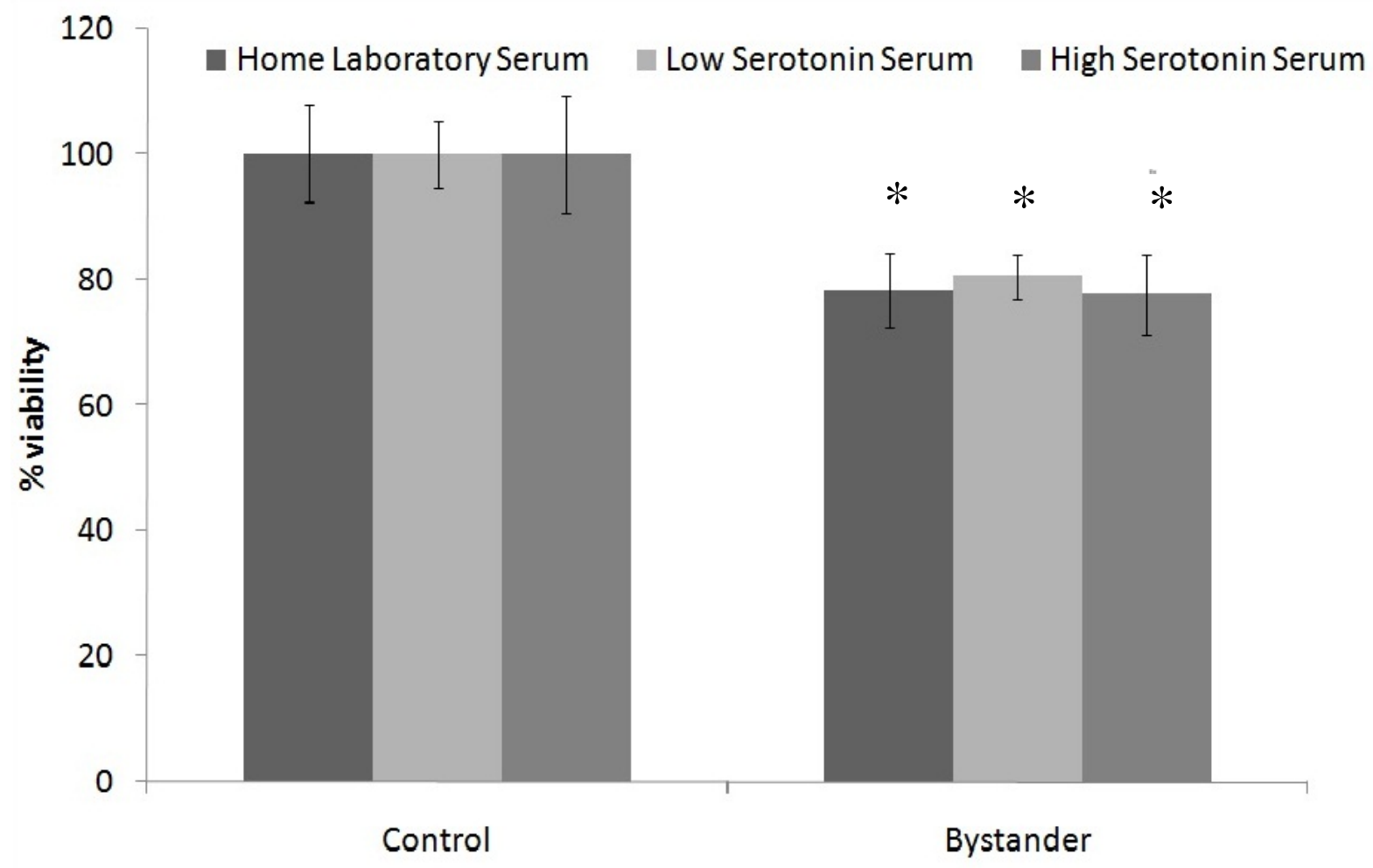

Figure 2 